\title{
Postpartum Haemorrhages: Targeting Mid-Genital Tract Anatomy
}

\author{
Hasan Yuksel (Corresponding author), \\ Aydın Adnan Menderes University, Faculty of Medicine, \\ Department of Obstetrics and Gynaecology, 09100 Aydın, Turkey. \\ E-Mail: drhyuksel@gmail.com \\ Emre Zafer \\ Aydın Adnan Menderes University, Faculty of Medicine, \\ Department of Obstetrics and Gynaecology, 09100 Aydın, Turkey.
}

\begin{abstract}
Mid-genital tract has some disadvantages in terms of both anatomy and physiology for controlling postpartum haemorrhage. The aetiology of postpartum haemorrhage is classified as 4Ts (tonus, tissue, trauma and thrombin). However, in 4T classification, different anatomic and physiologic characteristics of the genital tract are not taken into consideration. This critique suggests a modified nomenclature by adding specific anatomic location to etiologic information and aims to focus on postpartum mid-genital tract haemorrhages for the advanced learning. We have also discussed our approach to the mid-genital tract bleedings in an attempt to contribute to an improved management.
\end{abstract}

Keywords: Postpartum haemorrhage; uterine atony; placenta previa; placenta adhesion spectrum; genital trauma

\section{Special Issue of Health Sciences}

DOI: $10.7176 / J S T R / 6-03-26$

\section{Anatomic Location of Haemorrhage: Integrating into 4Ts}

Classically, postpartum haemorrhage (PPH) aetiology is described as acronym of 4Ts; (tonus, tissue, trauma and thrombin). This classification may give us a holistic description for the aetiology of PPH in medical education. Genital tract has several zones with different structural and physiologic characteristics and therefore PPH causes may differ depending on the anatomic zone(s). The 4T classification may have several weak points in this view. For example, vaginal and perineal haemorrhages have nothing to do with atony. Likewise, uterine inversion is not emphasized in $4 \mathrm{~T}$ classification as it does not point the bleeding location in genital tract. Thus, $4 \mathrm{~T}$ classification has some inadequate descriptions for clinical practice and for advanced learning.

In this context, PPH originated from mid-genital tract needs a special attention that takes its different anatomical and physiological characteristics into account. Additional definitions may be needed that would address both anatomy and aetiology. Then, as a suggestion, it would be appropriate to modify 4T classification, by especially addressing the presumed source of bleeding such as upper, middle and lower zones.

The aetiology and management of PPH based on genital tract zones are summarized in Table 1. Upper genital tract zone (uterine corpus) bleeding causes can be shown as "4Tin", indicating the relatively rare culprit, uterine inversions. Bleeding causes of mid-genital tract zone (lower uterine segment, cervix and upper vagina) would stay as $4 \mathrm{~T}$, including placenta previa (PP), with or without placenta adhesion spectrum (PAS), lower uterine segment atony (LUSA), cervical and deep vaginal tears. And finally, lower genital tract zone (vaginal and perineal) bleeding causes can be abbreviated as $2 \mathrm{~T}$, with referring to trauma and coagulation problems only. 
Table 1. Localization, aetiology and management of postpartum haemorrhages

\begin{tabular}{|c|c|c|}
\hline PPH Location & $\begin{array}{c}\text { T acronyms and Etiologic } \\
\text { Definitions }\end{array}$ & $\begin{array}{c}\text { Management } \\
\text { ( Fluids, Blood products, } \\
\text { hemostatics/procoagulants) }\end{array}$ \\
\hline $\begin{array}{c}\text { Zone I; Upper Level } \\
\text { Uterine Corpus }\end{array}$ & $\begin{array}{l}\text { 4Tin } \\
\text { Atony } \\
\text { Retained placental tissue } \\
\text { Lacerations } \\
\text { Coagulopathy } \\
\text { in, Uterine inversion }\end{array}$ & $\begin{array}{l}\text { Uterotonics, massage, } \\
\text { Curettage } \\
\text { Tamponade (balloon or others), } \\
\text { Compression sutures } \\
\text { Devascularization } \\
\text { Endovascular interventions } \\
\text { Uterine reposition (inversions) } \\
\text { Hysterectomy }\end{array}$ \\
\hline $\begin{array}{l}\text { Zone II; Mid-Level } \\
\text { LUS } \\
\text { Cervix } \\
\text { Apical Vagina }\end{array}$ & $\begin{array}{l}\text { LUSA } \\
\text { Placenta Previa ( } \pm \text { PAS) } \\
\text { Cervical lacerations } \\
\text { Vaginal apex and sulcus } \\
\text { lacerations } \\
\text { LUS (caesarean incision } \\
\text { extensions) } \\
\text { Coagulopathy }\end{array}$ & $\begin{array}{l}\text { May require interventions from both } \\
\text { above and below boxes with many } \\
\text { modifications (see Table } 3 \text { ) }\end{array}$ \\
\hline $\begin{array}{l}\text { Zone III; Lower Level } \\
\text { Lower vagina } \\
\text { Perineum }\end{array}$ & $\begin{array}{l}\text { 2T } \\
\text { Lacerations } \\
\text { Coagulopathy }\end{array}$ & $\begin{array}{l}\text { Haemostatic sutures } \\
\text { Tamponade (gauze, balloon) } \\
\text { Endovascular interventions (selective } \\
\text { embolization) }\end{array}$ \\
\hline
\end{tabular}

4T: Atony, Tissue (Placenta), Trauma, Thrombin; LUSA: lower uterine segment atony; PAS: placenta accreta spectrum

\section{Suggested Etiopathologic Classification of Postpartum Haemorrhage}

The proposed segmental approach may have a potential to improve the management of PPH and may contribute to the utilization of uniform terminology across medical literature. The segmental localization (zones) of bleeding combined with their possible aetiologies was rephrased and respective 4Ts were presented in Table 2.

Table 2. Nomenclature of postpartum haemorrhage

\begin{tabular}{|c|c|c|}
\hline \multirow{3}{*}{$\begin{array}{l}\text { Tonus, } \underline{\text { TA }} \\
\text { Tissue,TS } \\
\text { Trauma, } \underline{\text { TR }} \\
\text { Thrombin, } \underline{\text { TH }} \\
\underline{\text { Inversion, } \underline{\text { Tin }}}\end{array}$} & Zone 1 & $\begin{array}{l}\text { Z1TA,Uterine corpus atony } \\
\text { Z1TS, Retained placenta, PAS, ablation } \\
\text { Z1TR, Uterine corpus tear } \\
\text { Z1TH, Coagulopathy } \\
\text { Z1Tin, Inversion }\end{array}$ \\
\hline & Zone 2 & $\begin{array}{l}\text { Z2TA, LUSA } \\
\text { Z2TS, Placenta previa, PAS, ablation } \\
\text { Z2TR, Cervical, apical vaginal, LUS (CS Scar) lacerations } \\
\text { Z2TH, Coagulopathy }\end{array}$ \\
\hline & Zone 3 & $\begin{array}{l}\text { Z3TR, Vaginal/perineal lacerations } \\
\text { Z3TH, Coagulopathy }\end{array}$ \\
\hline
\end{tabular}

LUSA, lower uterine segment atony; PAS, placenta accreta spectrum; CS, Caesarean 


\section{Why to Focus on Mid-genital Tract Haemorrhages?}

Mid-genital tract (zone II) bleedings may be referred as "real challenge" where the presence of an experienced obstetric surgeon is a necessity in majority of cases. Instant fluid resuscitation with blood/blood products and or haemostatic/procoagulant agents is crucial in all PPH cases. The management of Zone II PPH except fluid and blood replacement is summarized in Table 3 and some manoeuvres in Figure 1.

Table 3. Management of postpartum mid-genital (Zone II) haemorrhage

\begin{tabular}{l}
$\begin{array}{l}\text { Anatomic location and } \\
\text { cause of bleeding }\end{array}$ \\
\hline
\end{tabular}

\begin{tabular}{ll}
\hline & $\begin{array}{l}\text { Bimanual compression (also during caesarean) } \\
\text { Cervical traction } \\
\text { Balloon (Foley) tamponade } \\
\text { Peri-cervical (fornix) tamponade with combinations with cervical } \\
\text { traction or balloon } \\
\text { Vaginal packing with suprapubic compression, if abdomen is open } \\
\text { tourniquet (use hands or ties) } \\
\text { Compression (Cho or others) sutures } \\
\text { Devascularization } \\
\text { Endovascular interventions } \\
\text { Hysterectomy }\end{array}$ \\
\hline Z2TS & As per previously published guidelines (e.g. RCOG) \\
\hline Z2TR & Repair, vaginal/cervical tamponade (balloon, gauze), or both \\
\hline S2TH & Stop bleeding, replace blood products, hemostatic/procoagulants \\
\hline
\end{tabular}

LUSA: lower uterine segment atony; PAS: placenta accreta spectrum; PP: Placenta previa.

In placenta-related bleedings of Zone II (such as Z2TS), the problem is generally diagnosed during immediate antenatal period. Therefore, precautions against PPH are taken during pregnancy in placental implantation or adhesion abnormalities. For example, a caesarean section mostly with midline uterine incision and fundal delivery of the foetus may be indicated.

Even though the medical management of PP and PAS were discussed in detail by RCOG Guideline, ${ }^{2}$ recommendations are not clear for situations when the pharmacological agents fail to stop bleeding. Recently, there are initiatives to guide the management of PAS. ${ }^{3,4}$ However, some recommendations are based on studies with relatively poor quality.

Placenta previa constitutes a substantial role in PPH causes. It seems that not all PP cases are the same in terms of anatomy and risk of haemorrhage. In the first group of PP cases, who had prior vaginal delivery in the past, or at least had a trial of labour that resulted in some cervical dilatation before going into caesarean delivery. When this group of women gets pregnant and PP is diagnosed, there is a high likelihood of placenta will invade through cervical canal, possibly down to the portio vaginalis. Most of the time, the uterine shape resembles to an hourglass particularly after delivery of foetus except in marginal or low-lying PP cases.

The other group of PP cases is the ones who had no prior vaginal delivery, trial of labour or cervical instrumentation history even though they might have had prior elective caesarean deliveries. In this second group of women, cervix is still in its natural anatomic shape, and internal cervical os is likely closed. When this group of women gets pregnant and PP is diagnosed, placenta will only be in contact with isthmus and internal cervical os without invading through cervical canal or deep in cervix. In this case, the shape of uterus resembles to a pear.

Obviously, the risk of PPH and the need for hysterectomy to control the bleeding are expected to be much higher in the first group. However, PAS may occur more frequently in the second group due to an existing 
uterine scar. A careful and meticulous evaluation of cervix and lower uterine segment by ultrasound helps in distinguishing between these two types.

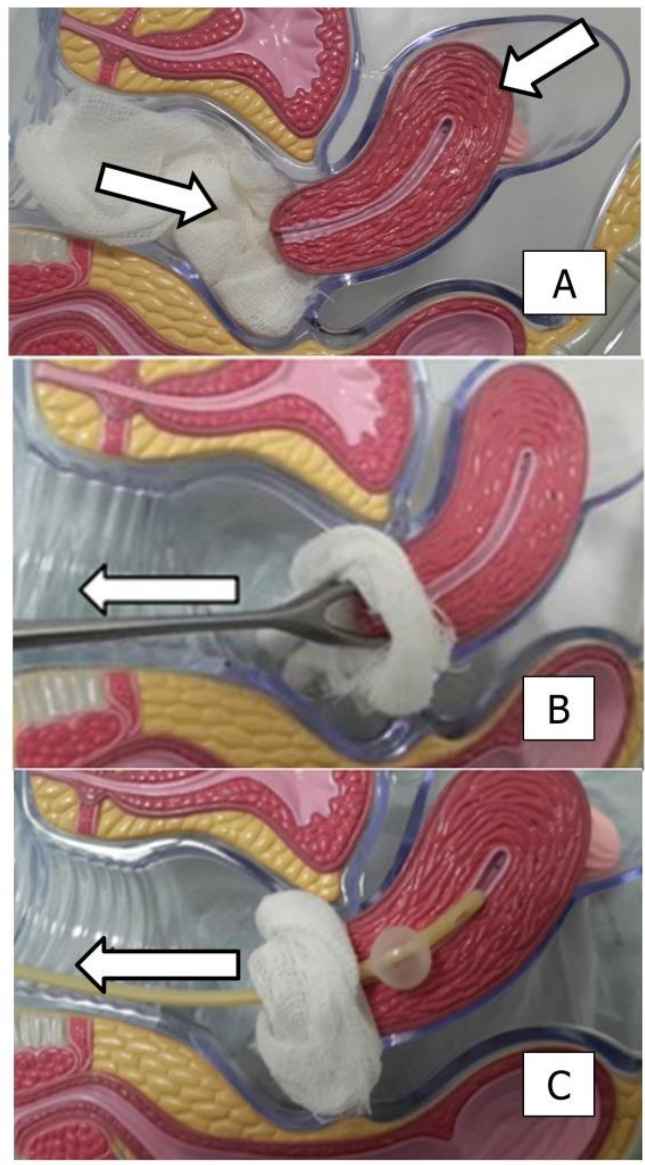

Figure 1.Bimanual compressions of the lower segment or vaginal packing manoeuvres are time saving and sometimes lifesaving (A). If the uterine corpus is well contracted in cases with Z2TA haemorrhage, holding the cervical lips with two ring forceps and pulling mild down distally is usually very effective. Gauze sponge compression can be placed to vaginal fornix to encircle the cervix for additional support (B) and a Foley balloon was added to previous manoeuvre for internal compression and peri-cervical gauze sponge placement for external compression can be very effective for both Z2TA and Z2TR haemorrhages $(\mathrm{C})$.

\section{Management of Mid-genital Zone Haemorrhages}

Management of Z2TA and Z2TR haemorrhages is also a challenging job. Possible helpful manoeuvres to compress vessels and myometrium may include balloon tamponade, gauze packing, compression sutures, applying pressure with hands or any instruments in every possible angle and side on the uterus. ${ }^{5-}$ ${ }^{11}$ The goal is to obstruct blood flow simply by squeezing and ligating the vessels and nearby myometrial tissue. This can be achieved by several manoeuvres which in our experience worked very well. Obviously, endovascular interventions can be an alternative when available.

In summary, the compression of Zone II vessels can be achieved in majority of cases by encircling the cervix with a gauze tamponade vaginally and placing a Foley balloon inside the lower uterine segment. Alternatively, after the placement of cervix-encircling gauze, a simple traction of cervix with ring forceps can be as effective. Here we present our approach for Z2TA (can also be utilized for Z2TR) haemorrhages step by step, starting after basic interventions such as intravenous fluids, uterotonics, blood products, hemostatics/procoagulants and urinary catheterization.

\section{Postvaginal Delivery Haemorrhages (Mid Genital Zone):}

1- Bimanual compression to lower uterine segment, one hand from vagina, the other from outer abdomen (suprapubic)

2- If uterine corpus contraction is normal: holding and pulling down the cervical lips with ring forceps distally. If bleeding stops, continue as needed 
3- If bleeding is continued and if feasible, Foley balloon insertion to isthmus and pulling down distally. Foley is preferred as others are excellent for uterine corpus atony, but they may miss isthmus and cervix. If Foley balloon placement is not feasible due to cervical dilatation or uterine contraction, attempting to narrow and distal traction of the cervix by ring forceps, placing cerclage or 3-9 o'clock sutures to keep Foley balloon in place.

4- If needed, packing up the vaginal fornix and surrounding the cervix by a gauze sponge in addition to items 3 and 4 to apply pressure both internally and externally

5- If the uterine corpus is well contracted, gauze packing of the vagina would achieve compression of the cervix/lower uterine segment between gauze and uterine corpus

6- Endovascular intervention (if available)

7- Laparotomy for compression sutures (Cho or others) or devascularization of mid-genital zone

8-Total abdominal hysterectomy

\section{During Caesarean section (Mid Genital Zone):}

1- If bleeding is profuse, placing tourniquet or manual constriction of lower uterine segment

2- Compressing lower uterine segment with hands, antero-posterior from abdomen or upwards from the vagina with compressing downward from abdomen.

3-Balloon insertion (Foley is preferred as others are excellent for uterine corpus atony but they may miss isthmus and cervix) and pulling the Foley catheter down distally

4- If needed, packing with gauze sponges surrounding the cervix at level of vaginal fornix to compress cervical and proximal vaginal vessels

5- Compression sutures (Cho or others), devascularization

6- Endovascular intervention (if available)

7- Total abdominal hysterectomy

\section{Conclusion}

As mid-genital tract bleedings are perhaps the most common PPH emergency consults, they warrant reviewing the available management approaches. The mid-segment of the genital tract has certain anatomic and physiologic differences form the rest of the tract. Hence, here we have suggested a modified nomenclature for PPH and discussed the possible benefit of adding anatomic location information to the 4T system. Also, we have shared our way of approach to mid-genital tract bleedings.

\section{References}

1. Panda B, Laifer S, Stiller R, Kleinman G. Primary atony of the lower uterine segment as a distinct cause of early postpartum hemorrhage: a case series and management recommendations. J Obstet Gynaecol 2009;29:628-32.

2. Jauniaux ERM, Alfirevic Z, Bhide AG, Belfort MA, Burton GJ, Collins SL, et al. Placenta Praevia and Placenta Accreta: Diagnosis and Management. Green-top Guideline No. 27a. BJOG 2018.

3. Allen L, Jauniaux E, Hobson S, Papillon-Smith J, Belfort MA. FIGO consensus guidelines on placenta accreta spectrum disorders: non conservative surgical management. Int J Gynaecol Obstet 2018;140: 281-90.

4. Collins SL, Alemdar B, van Beekhuizen HJ, Bertholdt C, Braun T, Calda P, et al. Evidence-based guidelines for the management of abnormally invasive placenta: recommendations from the International Society for Abnormally Invasive Placenta. Am J Obstet Gynecol 2019;220:511-526.

5. Cho JH, Jun HS, Lee CN. Hemostatic suturing technique for uterine bleeding during cesarean delivery.Obstet Gynecol 2000;96:129-31.

6. Chantrapitak W, Srijanteok K, Puangsa-art S. Lower uterine segment compression for management of early postpartum hemorrhage after vaginal delivery at Charoenkrung Pracharak Hospital. J Med Assoc Thai 2009;92:600-5. 
7. Ying H, Duan T, Bao YR, Song YH, Wang DF. Transverse annular compression sutures in the lower uterine segment to control postpartum hemorrhage at caesarean delivery for complete placenta previa. Int J Gynaecol Obstet 2010;108:247-8.

8. Chantrapitak W, Srijuntuek K, Wattanaluangarun R. The efficacy of lower uterine segment compression for prevention of early postpartum hemorrhage after vaginal delivery. J Med Assoc Thai 2011;94:649-56.

9. Yüksel H. A novel approach to primary lower uterine segment atony. Taiwan J Obstet Gynecol 2015;54:52-454.

10. Elagwany AMS, Dayem TMA. Primary lower uterine segment ballooning and atony as an unusual cause of postpartum hemorrhage. Arch Perinatal Med 2016;22:66-7.

11. Ramalingappa CA, DurgaSireesha U, Shruthi B. Paracervical clamps for treatment of uncontrolled postpartum haemorrhage: a novel technique. Int J Reprod Contracept Obstet Gynecol. 2018;7:3362-8 